Auburn University

Department of Economics

Working Paper Series

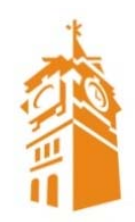

A UB URN

U N I V E R S I T Y

\title{
Assessing the Role of Sentiment in the Propagation of Fiscal Stimulus
}

Hyeongwoo Kim* and Bijie $\mathrm{Jia}^{+}$

"Auburn University, ${ }^{+}$College of Wooster

AUWP 2020-05

This paper can be downloaded without charge from:

http://cla.auburn.edu/econwp/

http://econpapers.repec.org/paper/abnwpaper/ 


\title{
Assessing the Role of Sentiment in the Propagation of Fiscal Stimulus*
}

\author{
Hyeongwoo $\mathrm{Kim}^{\dagger}$ and Bijie $\mathrm{Jia}^{\ddagger}$
}

August 2020

\begin{abstract}
This paper studies the dynamic effects of the fiscal policy shock on private activity using an array of vector autoregressive models for the post-war U.S. data. We are particularly interested in the role of consumer sentiment in the transmission of fiscal stimulus. Our major findings are as follows. Private spending fails to rise persistently in response to government spending shocks, while they exhibit persistent and significant increases when the sentiment shock occurs. Employing not only linear but also nonlinear state-dependent VAR model estimations, we show that the government spending shock generates consumer pessimism in all phases of business cycle resulting in subsequent decreases in private activity, which ultimately weakens the effectiveness of the fiscal policy. Our counterfactual simulation exercises confirm the important role of sentiment in propagating fiscal stimulus to private spending.
\end{abstract}

Keywords: Government Spending; Sentiment Channel;Nonlinear VAR; Counterfactual Simulations; Survey of Professional Forecasters

JEL Classification: E32; E62

*An earlier version of this paper was circulated under the title "Government Spending Shocks and Private Acitity: The Role of Sentiments." Our thanks go to seminar/conference participants at Xi'an Jiaotong University, Keio University, Bank of Korea, KEA International Conference, and Southern Economic Association Meetings. Special thanks go to Masao Ogaki, Ippei Fujiwara, Randy Beard, and Henry Thompson for helpful comments.

${ }^{\dagger}$ Patrick E. Molony Professor, Department of Economics, Auburn University, 138 Miller Hall, Auburn, AL 36849. Tel: (334) 844-2928. Fax: (334) 844-4615. Email: gmmkim@gmail.com.

${ }^{\ddagger}$ Department of Economics, College of Wooster, 213 Morgan Hall, Wooster, Ohio 44691. Tel: (330) 287-1948. Email: bjia@wooster.edu. 


\section{Introduction}

Observing the sluggish recovery from the recent Great Recession, the economics profession has revived the debate on the effectiveness of the fiscal policy in stimulating economic activity. Can increases in government spending help promote private spending? If so, will key variables of interest such as consumption and investment respond persistently positively to expansionary fiscal policy?

There is a large literature on this issue. One group of researchers reports positive responses of consumption, real wages, and output to expansionary fiscal shocks, which are roughly in line with key features of the New Keynesian macroeconomic model. See, among others, Rotemberg and Woodford (1992), Devereux, Head, and Laphan (1996), Fatás and Mihov (2001), Blanchard and Perotti (2002), Perotti (2005), Galí, López-Salido, and Vallés (2007). ${ }^{1}$

On the contrary, many other research works provide strong evidence of negative responses of consumption and real wages to fiscal spending shocks. See, for example, Aiyagari, Chirstiano, and Eichenbaum (1992), Hall (1986), Ramey and Shapiro (1998), Edelberg, Eichenbaum, and Fisher (1999), Burnside, Eichenbaum, and Fisher (2004), Cavallo (2005), Mountford and Uhlig (2009), Ramey (2012), and Owyang, Ramey, and Zubairy (2013). As Ramey (2011b) points out, these negative responses to an expansionary government spending shock are consistent with a negative wealth effect that often appears in the neoclassical macroeconomic model such as Aiyagari, Christiano, and Eichenbaum(1992) and Baxter and King (1993). ${ }^{2}$

One closely related literature focuses on the output multiplier of government spending. Empirical evidence is again mixed. For instance, Ramey and Shapiro (1998), Hall (2009), Barro and Redlick (2011), and Ramey (2011a) obtained fairly low government spending multiplier estimates, while Hall (2009) and Christiano, Eichenbaum, and Rebelo (2011) show that fiscal multipliers can be high when the nominal interest rate is bounded at zero. Overall, the range of fiscal multiplier estimates in the literature is very wide (Ramey, 2011a). Also, fiscal multiplier estimates seem to vary greatly across countries depending on key country characteristics such as the exchange rate regime and public indebtedness. See Corsetti, Meier, and Müller (2012) and Ilzetzki, Mendoza, and Vegh (2013) for details.

Another interesting question is whether the government spending shock is more powerful

\footnotetext{
${ }^{1}$ Consumption may rise in response to the government spending shock only in heavily restricted models. See, among others, Devereux, Head, and Laphan (1996) and Galí, López-Salido, and Vallés (2007).

${ }^{2}$ Increases in government spending may result in a negative wealth effect because government deficits may have to be financed by tax hikes in the future. Rational consumers reduce consumption and increase labor supply in response to spending shocks, resulting in a decrease in the real wage. Note that such responses would occur even when government raises revenues by non-distortionary lump-sum tax.
} 
during times of slack. Empirical evidence is again mixed. For example, Auerbach and Gorodnichenko (2012), Mittnik and Semmler (2012), and Fazzari, Morley, and Panovska (2015) report higher fiscal multipliers in a regime of a low economic activity than those in a high activity regime, whereas Owyang, Ramey, and Zubairy (2013) and Ramey and Zubairy (2014) find no such evidence.

Observing mixed empirical evidence on the effectiveness of fiscal stimulus, we study how the government spending shock influences private activity in the U.S. Finding negligibly weak or even negative responses of private activity to the fiscal spending shock, we introduce and highlight the role of consumer sentiment in the propagation of expansionary fiscal shocks to promote economic activity.

We are not the first who discuss the interaction between consumer sentiment and economic activity. Hall (1993) and Blanchard (1993), for example, underline the causal effects of animal spirit on economic activity in their explanation of the 1990-1991 recession. On the other hand, Cochrane (1994) points out that close relationship between innovations in consumer confidence and subsequent changes in economic activity may appear, because consumer confidence shocks reflect news about future economic productivity. Beaudry and Portier (2006, 2007) also propose similar news-driven business cycle models.

Barsky and Sims (2012) evaluate empirical relevance of these factors in explaining innovations in consumer confidence. They show that confidence innovations are better characterized by the news factor, even though animal spirit also has non-negligible contribution. Using a nonlinear VAR framework, Bachman and Sims (2012) report high fiscal multiplier estimates during periods of economic slack. They put an emphasis on the role of confidence, which embodies information of future productivity improvements in response to fiscal spending shocks during recessions. By the same token, they argue that consumers become more optimistic in response to the fiscal shock during times of slack, which contrasts sharply with our finding that reports solid negative responses of consumer sentiment to the fiscal shock in all phases of business cycle. In what follows, however, we demonstrate that their nonlinear evidence of consumer optimism completely vanishes when one uses properly detrended data.

We are particularly interested in the role of consumer sentiment in the propagation mechanism of the government spending shock to private activity such as consumption and investment, excluding the government component from the total GDP. For this purpose, we employ an array of identification methods for the fiscal shock including conventional recursively identified VAR models and the expectational VAR (EVAR) model of Ramey (2011b) that uses the survey of professional forecasters data (SPF). ${ }^{3}$ Our major findings are as follows.

\footnotetext{
${ }^{3}$ Perotti (2011) named Ramey's (2011b) model the expectational VAR model.
} 
First, we employ not only linear but also nonlinear, state-dependent VAR models with properly detrended data, and demonstrate that government spending shocks are not effective in stimulating private activity. That is, we report weak or even negative output effects of fiscal stimulus in all phases of business cycle. Consumption tends to respond positively only for a very short period of time, then rapidly decreases. Furthermore, initial increases in consumption are mainly driven by increases in nondurable good and services consumption. That is, when fiscal shocks are materialized, for example, via actual implementations of government purchases, consumers respond to it by buying more nondurable goods instead of durable goods because they view such increases in income as windfall. When changes in fiscal spending are allowed to be anticipated in the expectational VAR framework (Ramey, 2011b), we observe negligible or even negative responses of private spending, implying that fiscal policy shocks turn out to be mostly ineffective.

Second, we note that consumer sentiment rapidly deteriorates to a negative region since the impact of the fiscal spending shock, leading to subsequent decreases in consumption and investment. We report solid evidence that unexpected increases in government spending generate consumer pessimism which results in decreases in private spending, ultimately weakening the fiscal policy effect on the private sector GDP, again, in all phases of business cycle. Furthermore, we demonstrate that consumer sentiment leads private activity rather than it passively reflects the current state of the economy, implying an important role of a sentiment channel in the propagation mechanism of the fiscal spending shock.

Third, we provide further evidence in favor of an important role of the sentiment channel via counterfactual simulation exercises, employing the same VAR model by Bachman and Sims (2012) for an array of alternative identification schemes for the fiscal spending shock. Results strongly support substantial negative output effects of sentiment (pessimism) in response to fiscal policy shocks.

The remainder of this paper is organized as follows. Section 2 discusses our VAR models with alternative identification methods. We also discuss econometric features of our models as to the robustness of our empirical findings to alternative Wold ordering. In Section 3, we present a data description and our major empirical findings. We discuss the existence of the consumer sentiment channel in the fiscal policy propagation mechanism to stimulate private activity. Section 4 discusses the implications of our paper in comparison with other research works by implementing an array of nonlinear VAR model estimation as well as counterfactual simulation exercises. Results strongly supports the findings from our benchmark models. Section 5 concludes. 


\section{The Benchmark Empirical Model}

Abstracting from deterministic terms, we employ the following vector autoregressive (VAR) model. ${ }^{4}$

$$
\mathbf{x}_{t}=\sum_{j=1}^{p} \mathbf{A}_{j} \mathbf{x}_{t-j}+\mathbf{A}_{0}^{-1} \mathbf{u}_{t}
$$

where $\mathbf{A}_{0}^{-1}$ is the lower-triangular Choleski factor, and $\mathbf{u}_{t}$ is a vector of orthonormal structural shocks, $E \mathbf{u}_{t} \mathbf{u}_{t}^{\prime}=\mathbf{I}$. $\mathbf{x}_{t}$ is comprised of $\left(\mathbf{g}_{t}, \mathbf{y}_{t}, \mathbf{z}_{t}\right.$, sent $\left.t_{t}\right)$, the order of which we will vary to achieve identifications of the shocks. $\mathbf{g}_{t}$ is a vector of (or a scalar) government spending variables, $y_{t}$ is a scalar private activity variable such as consumption $\left(\right.$ conm $\left._{t}\right)$, investment $\left(\right.$ invt $\left._{t}\right)$, or the private GDP. sent $t_{t}$ is a scalar consumer sentiment variable, and $\mathbf{z}_{t}$ is a vector of control variables that includes the tax rate $\left(t r_{t}\right)$, the interest rate $\left(i_{t}\right)$, and the monetary aggregate $\left(m_{t}\right)$. All variables are demeaned and detrended, up to quadratic trend, prior to estimations. We limit our attention to a closed economy model so that we can compare our findings with others that use similar models in the current literature.

Motivated by Ramey's (2012) work, we employ VAR models based on alternative identification methods for the government spending shock. Our first model, FGOV, is similar to conventional recursively identified VAR models that identify the government spending shock by unexpected increases in federal government spending $\left(f_{g o v}\right)$. See, among others, Blanchard and Perotti (2002), Perotti (2005, 2008), and Galí, López-Salido, and Vallés (2007). Based on Perotti's (2011) suggestion, we employ $\mathbf{g}_{t}=\left[\text { fgov }_{t}, \text { tgov }_{t}\right]^{\prime}$, where tgov $_{t}$ denotes total government spending. Perotti (2011) claims that this specification is equivalent to Ramey's (2011b) expectational VAR (EVAR) model that is explained below, which considers a possibility that market participants are able to anticipate government spending ahead of time. ${ }^{5}$

It should be noted that we employ federal government total expenditures that include transfer payments in addition to government consumption and gross investment expenditures. $^{6}$ This is motivated by Oh and Reis' (2012) work that suggests an important role of targeted transfers during the Great Recession. Since transfers are considered automatic stabilizers, $\mathbf{g}_{t}$ is ordered next to $y_{t}$. The FGOV model is with the following $\mathbf{x}_{t}$.

$$
\mathbf{x}_{t}^{F G O V}=\left[y_{t}, \text { fgov }_{t}, \operatorname{tgov}_{t}, \mathbf{z}_{t}, \text { sent }_{t}\right]^{\prime}
$$

\footnotetext{
${ }^{4}$ Deterministic terms include an intercept and up to quadratic time trend. That is, we assume a jointly trend stationary VAR model.

${ }^{5}$ One may replace $\operatorname{tgov}_{t}$ with millitary spending.

${ }^{6} \mathrm{We}$ also used federal government consumption and gross investment expenditures for $g_{t}$, which produced qualitatively similar results.
} 
We also employ the so-called expectational VAR ( $E V A R)$ model, denoted the SPF model, that utilizes the survey of professional forecasters data, $\mathbf{g}_{t}=s p f_{t}$. Ramey (2011b) points out that recursively identified government spending shocks may not be appropriate because planned changes in fiscal spending variables such as military spending are likely to be anticipated by market participants before the government actually implements it. She constructed a news variable via the one-quarter ahead forecast error of fiscal spending growth rates, using the Survey of Professional Forecasters from the Philadelphia Fed. ${ }^{7} s p f_{t}$ is ordered first following Ramey (2011b). That is,

$$
\mathbf{x}_{t}^{S P F}=\left[\operatorname{spf} f_{t}, y_{t}, \mathbf{z}_{t}, \operatorname{sent}_{t}\right]^{\prime}
$$

Note that sent t $_{\text {is }}$ ordered last in all models unlike Bachman and Sims (2012) who put it in the middle of the VAR. This is because we attempt to identify the sentiment shock, being separated from its endogenous responses to other variables as much as possible. For this, we allow sent $t_{t}$ to respond to all other shocks by putting it last in the VAR, although our major findings are robust to alternative ordering used by Bachman and Sims (2012). ${ }^{8}$

It is well-known that econometric inferences from recursively identified VAR models might not be robust to alternative VAR ordering. It should be noted, however, that our major findings do not suffer from these issues. For example, in the SPF model (3), all response functions to the government spending $\left(s p f_{t}\right)$ shock and to the sentiment $\left(\right.$ sent $\left._{t}\right)$ shock are numerically identical even if we randomly shuffle all other variables. See Christiano, Eichenbaum, and Evans (1999) for details.

\section{$3 \quad$ Empirical Findings}

\subsection{Data Descriptions}

We use quarterly frequency data from 1960:I to 2013:II. We obtained most data from the FRED with a few exceptions. The consumer sentiment index $\left(\operatorname{sent}_{t}\right)$ is from University of Michigan's Survey of Consumers database. sent $t_{t}$ is a combination of its two sub-indices: the current economic conditions index (ICC) and the index of consumer expectations (ICE). That is, it reflects consumers' perception on the current state of the economy as well as economic conditions in the near future. All three indices are highly correlated each other,

\footnotetext{
${ }^{7}$ We do not employ her news variable that is constructed by changes in the expected present value of government spending, utilizing information from mass media sources. It is known that this variable may be uninformative for the post-war data. Results with this news variable are available in Jia and Kim (2016).

${ }^{8}$ See Jia and Kim (2016) for results with alternative ordering. We thank a referee and the editor for this suggestion.
} 
thus we report empirical findings mostly with the consumer sentiment index.

We use government total expenditures for $\mathbf{g}_{t}$ that includes transfer payments and interest payments as well as capital transfer payments. ${ }^{9}$ All public and private spending variables $\left(\right.$ tgov $_{t}$, fgov $_{t}$, conm $_{t}$, invt $\left._{t}\right)$ are in real per capita terms, divided by the GDP deflator and population, then log-transformed. sent $t_{t}$ is expressed in natural logarithm. $t r_{t}$ denotes federal tax receipts divided by the total GDP. As to the money market control variables, $i_{t}$ denotes the three month Treasury Bills yield and $m_{t}$ is the nominal M2, expressed in natural logarithm.

The Survey of Professional Forecasters data were obtained from the Philadelphia Fed. Starting from 1968:IV, forecasters were asked to predict nominal defense spending until 1981:II, whereas they were asked to predict real federal spending since then. We used the forecasts of the GDP deflator to convert the nominal defense spending data to real spending data. $^{10}$

We noticed that there were 9 changes of base year in the National Income and Product Account (NIPA) during our full sample period. Since the SPF forecast does not reflect such changes, we rescaled all relevant forecast data with 2009 as the common base year. ${ }^{11}$ Following Ramey (2011b), we proxy the government spending shock variable for the SPF model with the actual government spending growth $\left(\gamma_{g_{t}}\right)$ minus the forecast of it made one quarter earlier, that is, $\gamma_{g_{t}}-E\left(\gamma_{g_{t}} \mid \Omega_{t-1}\right)$ where $\Omega_{t-1}$ is the forecasters' information set at time $t-1$. We combine forecast errors of defense spending growth rates with those of federal spending growth rates in order to get the data with reasonably long sample period. As Ramey (2011b) discussed, this variable explains substantial portion of changes in the federal spending growth. Furthermore, we use forecast errors instead of forecasts, which will minimize the cost of combining those two data series. ${ }^{12}$

\footnotetext{
${ }^{9}$ Government total expenditures is a broader measure than government consumption and gross investment expenditures, which is the government component of the total GDP.

${ }^{10}$ Nominal defense spending data from 1968:IV to 1981:II are obtained from Tom Stark at the Philadelphia Fed.

${ }^{11}$ Ramey (2011b) and Forni and Gambetti (2016) used growth rates of government spending forecasts without adjusting for changes in base year. This is not ideal because their estimations can be influenced by 9 outliers (big changes due to changes in base year) in their fiscal spending variable.

${ }^{12}$ Our previous version paper investigated consequences of combining these two series using sub-sample analysis. Major findings from a shorter (homogeneous) sample period from 1981:III to 2013:II remain valid. We obtained similar impulse-response functions. Results are available in Jia and Kim (2016).
} 


\subsection{Government Spending Shocks and Private activity}

We first estimate the government spending effect on the private GDP $\left(p g d p_{t}\right)$ that excludes the government consumption and gross investment from the total GDP. ${ }^{13}$ Figure 1 reports the response function estimates of the private GDP to the fiscal spending shock and to the sentiment shock using the two models presented in the previous section. We also report the $95 \%$ confidence bands obtained from 500 nonparametric bootstrap simulations from the empirical distribution.

As can be seen in the first column of Figure 1, the government spending shock has negligible or even negative effects on the private GDP in both models we consider, which is consistent with the findings by Ramey (2012). This implies that positive responses of the total GDP, if any, to the fiscal shock are likely to be driven by an expansion of the public sector. ${ }^{14}$ Contrary to the fiscal shock, the sentiment shock yields persistently positive effects (second column) on the private GDP for almost 3 years, which is significant at the $5 \%$ level.

We note that these findings are consistent with the work by Hall (1993), Blanchard (1993), Cochrane (1994), and Bachman and Sims (2012), in the sense that we find a close relationship between sentiment and private economic activity. However, as we can see in the third column, our findings contrast sharply with those of Bachman and Sims (2012) who claim that the government spending shock has a positive effect on consumer confidence during times of slack. ${ }^{15}$ Put it differently, we report solid evidence of consumer pessimism in all models that may explain why the fiscal policy fails to stimulate private activity. In Section 4, we show that these findings remain valid even in nonlinear, state-dependent VAR models that were used by Bachman and Sims (2012) when one uses properly detrended data.

\section{Figure 1 around here}

Next, we report impulse-response function estimates of private consumption $\left(\mathrm{conm}_{t}\right)$ and investment $\left(\right.$ invt $\left._{t}\right)$ to the fiscal spending shock in Figure 2. Consumption responds significantly positively for about a quarter, then starts deteriorating rapidly under the $F G O V$ identification scheme, while no meaningful responses were observed when the $S P F$ model is employed. Investment responses to the fiscal spending shock turn out to be mostly negligible and insignificant. These responses of consumption and investment are consistent with negligible and even negative responses of the private GDP to the government spending shock reported in Figure 1.

\footnotetext{
${ }^{13}$ We use three lags for our VAR estimations based on the Akaike Information Criteria with a maximum 4 lags.

${ }^{14}$ Responses of the total GDP to the government spending shock are available upon request.

${ }^{15}$ They report negligible responses of consumer confidence during economic booms.
} 
On the other hand, consumption and investment respond significantly positively to the sentiment shock for a prolonged period of time in both models. That is, we obtained solid evidence of the persistently positive sentiment effects on private activity.

\section{Figure 2 around here}

\subsection{Responses of Durable and Nondurable Goods Consumption}

One of our objectives is to identify the propagation channel of the fiscal spending shock to promote private activity. We view the consumer sentiment as a potential candidate. As we've seen in Figure 1, consumer sentiment rapidly falls below zero immediately after the government spending shock occurs, which might play a key role in explaining why initially positive responses of consumption rapidly deteriorate to a negative area.

Sudden and large increases in government spending may be interpreted as a sign of weak economy and may spread a feeling of pessimism, causing private spending to decrease. Naturally, such changes in consumer sentiment will ultimately weaken the effectiveness of the expansionary fiscal policy as consumption and investment decline.

We note that the total consumption $\left(\right.$ conm $\left._{t}\right)$ responses in Figure 2 resemble those of nondurable goods and services consumption $\left(\right.$ conn $\left._{t}\right)$ rather than IRFs of durable goods consumption $\left(\right.$ cond $\left._{t}\right)$ that are reported in Figure 3. That is, consumption responses to the fiscal shock seem to be mainly driven by temporary changes in nondurable goods consumption.

One potentially interesting interpretation of these results is the following. When government spending is allowed to be anticipated as in the SPF model, the government spending shock generates consumer pessimism, resulting in decreases or no meaningful changes in consumption. When fiscal shocks are actually materialized, that is, when identified fiscal shocks are the same as the actual increases in fiscal spending as in the FGOV model, consumers respond to it by increasing nondurable goods consumption because they view increases in income as windfall. Since consumers tend to be reluctant to buy durable goods such as automobiles and home appliances unless they are optimistic about their income in the near future, these findings imply that fiscal shocks fail to generate consumer optimism on future economic conditions.

On the other hand, all consumption $\left(\operatorname{conm}_{t}, \operatorname{cond}_{t}, \operatorname{conn}_{t}\right)$ respond significantly positively and persistently when the sentiment shock occurs no matter what models are employed.

Figure 3 around here 


\subsection{Government Spending Shock and the Role of the Sentiment Channel}

We observe solid positive effects of the sentiment shock on private spending in both models. We note that these findings may provide useful insights on the ineffectiveness of the fiscal policy in promoting private activity as reported in the previous section. That is, the fiscal spending shock may not be able to stimulate consumption and investment if it fails to generate optimism. In other words, the effectiveness of the fiscal spending shock may critically hinge upon a sentiment channel.

Observing sudden increases in the government deficit, consumers may revise their economic growth forecasts downwards, interpreting such policy actions as a clear sign of serious economic downturns to come. In this sense, our conjecture is consistent with the news effect discussed in Cochrane (1994) and Bachman and Sims (2012), even though Bachman and Sims (2012) are more optimistic on the role of expansionary fiscal policy.

One may argue against this conjecture by the following logic. Consumption and investment may fall after the spending shock occurs for some unknown reason. Sentiment may fall passively reflecting such decreases in the private GDP. Although this is a feasible story, we are skeptical of this possibility for the following reasons.

Consumption tends to rise for a short period of time in response to the fiscal shock (see Figures 2 and 3), whereas consumer sentiment falls almost immediately (see Figure 1) on impact of the shock. These responses are inconsistent with the view that consumer sentiment passively reflects changes in the current private GDP. If that is the case, the sentiment response should have resembled the initially positive responses of consumption for about a year since the impact of the fiscal shock.

Furthermore, it should be noted that the consumer sentiment index is constructed to measure consumers' perception on the future economic conditions as well as the current conditions. Therefore, immediate decreases of the sentiment and short-run increases in consumption jointly imply that consumer sentiment does not passively reflect changes in private activity. Put it differently, our response function estimates imply the existence of the sentiment channel where sentiment plays a leading role in determining private activity.

\subsection{Robustness Check with Sub-Sample Analyses}

This subsection implements a robustness check analysis for our key findings over different sample periods, employing a fixed-size rolling window scheme described as follows.

We begin with estimations of our VAR models (2) and (3) to obtain the first set of impulse-response functions using the initial $T_{0}<T$ observations, $\left\{\mathbf{x}_{t}\right\}_{t=1}^{T_{0}}$. Then, we move 
the sample period of the data forward by adding one more observation to the sample but dropping one earliest observation, $\left\{\mathbf{x}_{t}\right\}_{t=2}^{T_{0}+1}$, then re-estimate the response functions. We repeat this until we utilize the last set of observations, $\left\{\mathbf{x}_{t}\right\}_{t=T-T_{0}+1}^{T}$. Note that we maintain the same number of observations $\left(T_{0}\right)$ throughout the whole exercises.

We report some results in Figure 4 employing a 30-year rolling window scheme that corresponds to 120 quarterly observations. The $x$-axis (Date) is a sequence of the 30-year rolling windows indexed from 1989:IV to 2013:II, whereas the $y$-axis (Year) is the time horizon of the response function indexed from 0 to 5 years. Lighter surface areas denote negative responses of private GDP to the fiscal spending shock, while darker areas are positive responses.

Results overall confirm our previous findings using the full sample period. In response to the government spending shock, private GDP declines at least in the short-run in both models, then slowly adjusts to the new long-run equilibrium. ${ }^{16}$ The sentiment shock, on the other hand, stimulate private spending persistently since the impact of the shock. ${ }^{17}$

\section{Figure 4 around here}

\section{Comparisons with Other Works}

This section provides robustness analyses using alternative specifications to help understand our findings in comparison with those of other influenctial works in the current literature. For this purpose, we provide results from an array of counterfactual simulation exercises as well as nonlinear, state-dependent VAR models that allow regime-specific impulse-response analysis.

We follow the framework proposed by Bachman and Sims (2012) who argue that fiscal spending shocks generate consumer optimism during times of slack. Also, we employ discretionary components of government expenditure variables such as federal government consumption and gross investment expenditures instead of the total expenditures that were used in our previous analysis.

With properly detrended data, our exercises upset their findings, and confirm the results presented earlier in the present paper. We report virtually no evidence of nonlinearity, which is consistent with findings by Owyang, Ramey, and Zubairy (2013) and Ramey and Zubairy (2014), but provides a stark contrast with the implications of Auerbach and Gorodnichenko

\footnotetext{
${ }^{16}$ Although the responses become positive in longer-run, they are mostly insignificant.

${ }^{17}$ Results are available upon request.
} 
(2012), Mittnik and Semmler (2012), Fazzari, Morley, and Panovska (2015), among others. Consumer sentiment responds overall negatively to fiscal spending shocks in all regimes unlike the work of Bachman and Sims (2012). Our simulation exercises demonstrate an important role of the sentiment channel.

\subsection{Nonlinear Model Estimates}

We first re-visit the possibility that fiscal policy is more effective during recessions. Following Auerbach and Gorodnichenko (2012) and Bachman and Sims (2012), we employ a nonlinear, state-dependent VAR model that allows regime-specific fiscal policy effects on private spending.

One important point to make is the following. Unlike Bachman and Sims (2012) who demean the data in the VAR, we demean and detrend all data $\mathbf{x}_{t}$ prior to estimations because $\mathbf{g}_{t}$ and $\mathrm{y}_{t}$ are clearly trending upward as can be seen in Figure $5 .{ }^{18,19}$ Without proper detrending, estimations of the impulse-response function may not be legitimate in the presence of trend, because the VAR system may contain a unit root or a near unit root that can generate explosive response functions. To check this possibility, we calculated eigenvalues of the VAR system with an intercept only, which confirmed our conjecture. On the other hand, eigenvalues of the VAR with an intercept and time trend were all less than one in modulus. ${ }^{20}$

\section{Figure 5 around here}

Based on this, our nonlinear VAR model with demeaned and detrended data is the following.

$$
\mathbf{x}_{t}=\sum_{j=1}^{p} \mathbf{A}_{1, j} \mathbf{x}_{t-j}+\sum_{j=1}^{p} \mathbf{A}_{2, j} \mathbf{x}_{t-j} z_{t-j}+\sum_{j=1}^{p} \mathbf{A}_{3, j} \mathbf{x}_{t-j} z_{t-j}^{2}+\mathbf{A}_{0}^{-1} \mathbf{u}_{t}
$$

where

$$
\begin{aligned}
& E \mathbf{A}_{0}^{-1} \mathbf{A}_{0}^{-1^{\prime}}=\boldsymbol{\Sigma}_{t},\left(E \mathbf{u}_{t} \mathbf{u}_{t}^{\prime}=I\right), \\
& \boldsymbol{\Sigma}_{t}=\boldsymbol{\Sigma}_{e}\left(1-f\left(z_{t-1}\right)\right)+\boldsymbol{\Sigma}_{r}\left(f\left(z_{t-1}\right)\right),
\end{aligned}
$$

\footnotetext{
${ }^{18}$ We include up to quadratic trend in addition to an intercept and linear trend. Results are similar as long as an intercept and linear trend are present.

${ }^{19}$ We used the government consumption and gross investment expenditures for $g_{t}$ to be comparable with empirical findings reported by Bachman and Sims (2012).

${ }^{20}$ Results are available from authors upon request.
} 
and $z_{t}$ is a standardized seven quarter backward moving average of the real GDP growth. $f\left(z_{t}\right)$ is defined as follows,

$$
f\left(z_{t}\right)=\frac{\exp \left(-\gamma z_{t}\right)}{1+\exp \left(-\gamma z_{t}\right)}, \gamma>0
$$

$f\left(z_{t}\right)$ is a probability measure of being in recession given $z_{t}$. Note that the Choleski factor varies with the state of the economy because $\boldsymbol{\Sigma}_{t}$ is a weighted average of the variance covariance matrices, $\boldsymbol{\Sigma}_{e}$ (boom) and $\boldsymbol{\Sigma}_{r}$ (recession). ${ }^{21}$

In Figure 6, we report the response function estimates of the private GDP (first row) and of the total GDP (second row) to the fiscal spending shock identified with federal government consumption and gross investment $\left(f c \& i_{t}\right)$ and federal government defense spending $\left(d e f n_{t}\right)$ as well as federal government total spending $\left(f g o v_{t}\right) .{ }^{22}$ Note that the model with $f c \& i_{t}$ and the total GDP $\left(g d p_{t}\right)$ corresponds to the one reported in Bachman and Sims (2012) except that we detrended the data prior to estimations. ${ }^{23}$

Solid lines are the response function in the recession regime, while dashed lines are 15.87 percentiles, 50 percentiles, and 84.13 percentiles of the response function in the boom regime, which constitutes the one standard deviation confidence band, generated by 500 nonparametric bootstrap simulations. We report one standard deviation bands as in Bachman and Sims (2012). However, having a 95\% confidence band does not change the results because the $95 \%$ confidence band is wider than the one standard deviation (68\%) band, thus the recession response functions must be still contained inside the band.

We obtain solid negative effects of the fiscal spending shock on private spending in both regimes from all models we consider. Furthermore, we fail to find any regime-specific fiscal policy effects on private activity, which provides a stark contrast with empirical results presented by Bachman and Sims (2012).

\section{Figure 6 around here}

In Figure 7, we also report the response function point estimates of sent $t_{t}$ to the fiscal shock in the recession regime along with the one standard deviation confidence band of the

\footnotetext{
${ }^{21}$ Eric Sims kindly provided his code with the data. Following their work, we set $\gamma=1.5$ and recession is defined when $f\left(z_{t}\right) \geq 0.8$. For detailed explanations on estimations, see Bachman and Sims (2012).

${ }^{22}$ Following Bachman and Sims (2012), we report regime-specific impulse-response function estimates. For more rigorous analysis, we need to estimate the generalized impulse-response functions for nonlinear models (Koop, Pesaran, and Potter, 1996).

${ }^{23}$ Our analysis utilizes a longer sample period. However, as we showed in previous section, our major findings are robust to alternative sample periods.
} 
response function in the boom. Again, we fail to find evidence of nonlinearity. sent $t_{t}$ exhibits either negligible or even negative (especially with the total GDP) similar responses in both regimes no matter what identification schemes are used.

In a nutshell, we obtained virtually no evidence of nonlinearity, employing similar VAR models in Bachman and Sims (2012) but with properly detrended data. We confirmed consumer pessimism and weak propagation mechanisms of expansionary fiscal spending policy from the linear model. Put it differently, our major findings are overall consistent with the work of Owyang, Ramey, and Zubairy (2013) and Ramey and Zubairy (2014) who also reported weak evidence of nonlinearity.

\section{Figure 7 around here}

\subsection{Counterfactual Simulation Results}

This section implements counterfactual simulation exercises that isolate the direct effects of the fiscal expansion shock on private activity from its indirect effects via changes in sentiment. For this purpose, we generate a hypothetical sequence of sentiment shocks that holds sentiment unchanged at all forecast horizons since the impact of the fiscal shock, which will be used to eliminate the indirect effects of the fiscal shock so that one can obtain the hypothetical direct fiscal shock effects on private activity. Similar approaches were used in Bachman and Sims (2012), Kilian and Lewis (2011), Sims and Zha (2006), Bernanke, and Gertler, and Watson (1997).

Following Bachman and Sims (2012), we employ the following tri-variate VAR model.

$$
\mathbf{x}_{t}=\sum_{j=1}^{p} \mathbf{A}_{j} \mathbf{x}_{t-j}+\mathbf{A}_{0}^{-1} \mathbf{u}_{t}
$$

where $\mathbf{x}_{t}=\left[\begin{array}{lll}g_{t} & \text { sent } & y_{t}\end{array}\right]^{\prime}$. Note that they used different ordering from ours presented earlier in (2) and (3).

Let $\tilde{\mathbf{F}}$ denotes the top-left 3 by 3 sub-matrix of the $3 p$ by $3 p$ companion matrix for the state-space representation. ${ }^{24}$ The $h$-period ahead impulse-response function of the $i^{\text {th }}$ variable to the structural shock to the $j^{\text {th }}$ variable is given by the following.

$$
\psi_{i, j}(h)=s_{i}^{\prime} \tilde{\mathbf{F}}^{h-1} \mathbf{A}_{0}^{-1} s_{j},
$$

\footnotetext{
${ }^{24}$ See any time series econometrics textbook for details on the state-space representation.
} 
where $s_{i}$ is a 3 by 1 selection vector with a one in the $i^{\text {th }}$ place and zeros elsewhere.

The contemporaneous sentiment response to a $1 \%$ fiscal spending shock $\left(u_{1}^{g}=1\right)$ is given by $s_{2}^{\prime} \mathbf{A}_{0}^{-1} s_{1}$. To zero out this response, we need to generate the following size hypothetical sentiment shock,

$$
u_{1}^{s e n t}=-\frac{s_{2}^{\prime} \mathbf{A}_{0}^{-1} s_{1}}{s_{2}^{\prime} \mathbf{A}_{0}^{-1} s_{2}}
$$

The sequence of sentiment shocks for the remaining period can be recursively calculated as follows.

$$
u_{h}^{\text {sent }}=-\frac{s_{2}^{\prime} \tilde{\mathbf{F}}^{h-1} \mathbf{A}_{0}^{-1} s_{1}+\sum_{r=1}^{h-1}\left(s_{2}^{\prime} \tilde{\mathbf{F}}^{h-r} \mathbf{A}_{0}^{-1} s_{2}\right) u_{r}^{\text {sent }}}{s_{2}^{\prime} \mathbf{A}_{0}^{-1} s_{2}}, h=2,3, \ldots
$$

Finally, the counterfactual impulse-response function of the $i^{\text {th }}$ variable to the $1 \%$ fiscal spending shock can be calculated as follows.

$$
\hat{\psi}_{i, 1}(h)=\psi_{i, 1}(h)+\sum_{r=1}^{h}\left(s_{i}^{\prime} \tilde{\mathbf{F}}^{h-r} \mathbf{A}_{0}^{-1} s_{2}\right) u_{r}^{s e n t}
$$

It should be noted that we employ the same VAR model that are used in Bachman and Sims (2012) to understand what account for the differences between theirs and ours. For this, we use the same government spending variable as theirs, federal government consumption and gross investment expenditures $\left(f c \& i_{t}\right)$. In addition, we employ federal government defense spending $\left(\right.$ de $\left.f n_{t}\right)$ and state and local government consumption and gross investment expenditures $\left(s c \& i_{t}\right)$.

In Figure 8, we report hypothetical response functions (solid lines) $\hat{\psi}_{i, 1}(h)$. Dashed lines are the unconstrained impulse-response functions $\psi_{i, 1}(h)$ and their $95 \%$ confidence bands from 500 nonparametric bootstrap simulations. As can be seen in the first column, sentiment responses are completely turned off (solid lines) after we add the sequence of hypothetical sentiment shock in (9). Note that these additional sentiment shocks are mostly positive

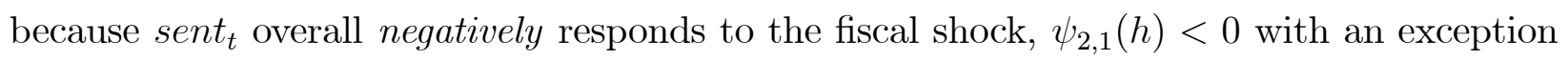
of the case with $s c \& i_{t}$ in the short-run. Since these hypothetical consumer optimism shocks, $u_{h}^{\text {sent }}>0$, continue to boost output, hypothetical responses of the private GDP (solid lines) in the second column are overall greater than original responses (dashed lines), that is, $\hat{\psi}_{1,3}(h)>\psi_{1,3}(h)$, which implies that the propagation of the fiscal spending shock might be weakened as it creates consumer pessimism. It is interesting to see that the $s c \& i_{t}$ shock generates consumer optimism in the short-run, creating some stimulus on private spending.

Our empirical results contrast sharply with those of Bachman and Sims (2012), even when we used the same identification scheme. With properly detrended data, the federal government spending shock consistently generates consumer pessimism, which weakens the 
propagation of expansionary fiscal policy shocks to promote economic activity.

\section{Figure 8 around here}

\section{Conclusion}

The recent Great Recession accompanied by the slow recovery triggered an active debate on the effectiveness of the fiscal policy in stimulating economic growth. Empirical evidence is at best mixed and the economics profession has failed to reach a consensus.

This paper takes a different road and attempts to identify important propagation channels of the fiscal policy to stimulate the economy. For this purpose, we attempt to evaluate the role of consumer sentiment in the effectiveness of expansionary government spending shock on economic activity in the private sector. As Ramey (2011b) points out, statistical inferences may be influenced by alternative identification methods for the spending shock. Thus, we employ an array of recursively identified VAR models as well as the expectational VAR model. We obtain solid evidence of the existence of a consumer sentiment channel that ultimately weaken the output effect of fiscal policy.

We note that consumer sentiment negatively responds to the government spending shock since the impact, while under the recursively identified VAR models, consumption rises in the short-run, mainly due to an increase in nondurable good consumption, then quickly deteriorates to a negative region. That is, sentiment leads changes in consumption instead of passively reflecting changes in economic conditions. This implies that the fiscal policy may be ineffective in stimulating economic activity because it generates consumer pessimism that ultimately decreases consumption and investment.

Our findings contrast sharply with those of Bachman and Sims (2012) who argue that ex-

pansionary fiscal policy can promote economic activity via consumer optimism during recessions. Using the same nonlinear, state-dependent VAR model, but with properly detrended data, we demonstrate such evidence completely disappears. Counterfactual simulation exercises confirm an important role of consumer pessimism in the propagation mechanism of the fiscal shock. 


\section{References}

Aiyagari, S. R., L. J. Christiano, and M. Eichenbaum (1992): "The output, employment, and interest rate effects of government consumption," Journal of Monetary Economics, 30 .

Auerbach, A. J., and Y. Gorodnichenko (2012): "Measuring the Output Responses to Fiscal Policy," American Economic Journal: Economic Policy, 4(2), 1-27.

Bachmann, R., and E. R. Sims (2012): "Confidence and the transmission of government spending shocks," Journal of Monetary Economics, 59, 235-249.

BARRo, R. J., And C. J. Redlick (2011): "Macroeconomic effects from government purchases and taxes," The Quarterly Journal of Economics, 126(1), 51-102.

Barsky, R. B., And E. R. Sims (2012): "Information, animal spirits, and the meaning of innovations in consumer confidence," American Economic Review, 102(4), 1343-77.

Baxter, M., And R. G. King (1993): "Fiscal policy in general equilibrium," American Economic Review, 83(3), 315-34.

Beaudry, P., and F. Portier (2006): "Stock prices, news, and economic fluctuations," American Economic Review, 96(4), 1293-1307.

- (2007): "When can changes in expectations cause business cycle fluctuations in neo-classical settings?," Journal of Economic Theory, 135(1), 458-477.

Bernanke, B. S., M. Gertler, and M. Watson (1997): "Systematic Monetary Policy and the Effects of Oil Price Shocks," Brookings Papers on Economic Activity, 28(1), 91157.

Blanchard, O. (1993): "Consumption and the Recession of 1990-1991," American Economic Review, 83(2), 270-74.

Blanchard, O., and R. Perotti (2002): "An empirical characterization of the dynamic effects of changes in government spending and taxes on output," in The Quarterly Journal of Economics, pp. 1329-1368. MIT Press.

Burnside, C., M. Eichenbaum, and J. D. M. Fisher (2004): "Fiscal shocks and their consequences," Journal of Economic Theory, 115(1), 89-117. 
Cavallo, M. (2005): "Government employment and the dynamic effects of fiscal policy shocks," Working Paper Series 2005-16, Federal Reserve Bank of San Francisco.

Christiano, L., M. Eichenbaum, and S. Rebelo (2011): "When Is the Government Spending Multiplier Large?," Journal of Political Economy, 119(1), 78 - 121.

Christiano, L. J., M. Eichenbaum, and C. L. Evans (1999): "Monetary policy shocks: What have we learned and to what end?," in Handbook of Macroeconomics, ed. by J. B. Taylor, and M. Woodford, vol. 1 of Handbook of Macroeconomics, chap. 2, pp. 65-148. Elsevier.

Cochrane, J. H. (1994): "Shocks," Carnegie-Rochester Conference Series on Public Policy, 41(1), 295-364.

Corsetti, G., A. Meier, and G. J. MüLler (2012): "What determines government spending multipliers?," Economic Policy, 27(72), 521-565.

Devereux, M. B., A. C. Head, and B. J. Lapham (1996): "Monopolistic competition, increasing returns, and the effects of government spending," Journal of Money, Credit and Banking, 28(2), 233-54.

Edelberg, W., M. Eichenbaum, and J. D. Fisher (1999): "Understanding the effects of a shock to government purchases," Review of Economic Dynamics, 2(1), 166-206.

Fatás, A., And I. Mihov (2001): "The effects of fiscal policy on consumption and employment: Theory and evidence," CEPR Discussion Papers 2760, C.E.P.R. Discussion Papers.

Fazzari, S. M., J. Morley, and I. Panovska (2015): "State-dependent effects of fiscal policy," Studies in Nonlinear Dynamics \& Econometrics, 19(3), 285-315.

Forni, M., and L. Gambetti (2016): "Government spending shocks in open economy VARs," Journal of International Economics, 99(C), 68-84.

Galí, J., J. D. López-Salido, and J. VAllés (2007): "Understanding the effects of government spending on consumption," Journal of the European Economic Association, $5(1), 227-270$.

Hall, R. E. (1986): "The role of consumption in economic fluctuations," in The American Business Cycle: Continuity and Change, NBER Chapters, pp. 237-266. National Bureau of Economic Research, Inc. 
Hall, R. E. (1993): "Macro theory and the recession of 1990-1991," American Economic Review, 83(2), 275-79.

HALL, R. E. (2009): "By how much does GDP rise if the government buys more output?," Brookings Papers on Economic Activity, 40(2), 183-249.

Ilzetzki, E., E. G. MendozA, And G. A. VeGh (2013): "How big (small) are fiscal multipliers?," Journal of Monetary Economics, 60, 239-254.

JiA, B., AND H. KIM (2016): "Government spending shocks and private activity: The role of sentiment," MPRA Working Paper No. 71554.

Kilian, L., And L. T. Lewis (2011): "Does the Fed Respond to Oil Price Shocks?," Economic Journal, 121(555), 1047-1072.

Koop, G., M. H. Pesaran, and S. M. Potter (1996): "Impulse response analysis in nonlinear multivariate models," Journal of Econometrics, 74(1), 119-147.

Mittnik, S., And W. Semmler (2012): "Regime dependence of the fiscal multiplier," Journal of Economic Behavior and Organization, 83, 502-522.

Mountford, A., And H. Uhlig (2009): "What are the effects of fiscal policy shocks?," Journal of Applied Econometrics, 24(6), 960-992.

$\mathrm{OH}$, H., AND R. REIS (2012): "Targeted transfers and the fiscal response to the great recession," Journal of Monetary Economics, 59(S), 50-64.

Owyang, M. T., V. A. Ramey, and S. Zubairy (2013): "Are government spending multipliers greater during periods of slack? Evidence from 20th century historical data," NBER Working Papers 18769, National Bureau of Economic Research, Inc.

Perotti, R. (2005): "Estimating the effects of fiscal policy in OECD countries," Proceedings.

(2008): "In search of the transmission mechanism of fiscal policy," in NBER Macroeconomics Annual 2007, Volume 22, NBER Chapters, pp. 169-226. National Bureau of Economic Research, Inc.

- (2011): "Expectations and fiscal policy: An empirical investigation," Manuscript.

RAmey, V. A. (2011a): "Can government purchases stimulate the economy?," Journal of Economic Literature, 49:3, 673-685. 
_ (2011b): "Identification government spending shocks: It's all in the timing," The Quarterly Journal of Economics, 126(1), 1-50.

_ (2012): "Government Spending and Private Activity," in Fiscal Policy after the Financial Crisis, NBER Chapters, pp. 19-55. National Bureau of Economic Research, Inc.

Ramey, V. A., and M. D. Shapiro (1998): "Costly capital reallocation and the effects of government spending," Carnegie-Rochester Conference Series on Public Policy, 48(1), 145-194.

Ramey, V. A., and S. Zubairy (2014): "Government spending multipliers in good times and in bad: Evidence from U.S. historical data," NBER Working Papers 20719, National Bureau of Economic Research, Inc.

Rotemberg, J. J., and M. Woodford (1992): "Oligopolistic pricing and the effects of aggregate demand on economic activity," Journal of Political Economy, 100(6), 1153-1207.

Sims, C. A., and T. Zha (2006): "Does Monetary Policy Generate Recessions?," Macroeconomic Dynamics, 10(02), 231-272. 
Figure 1. Responses of the Private GDP
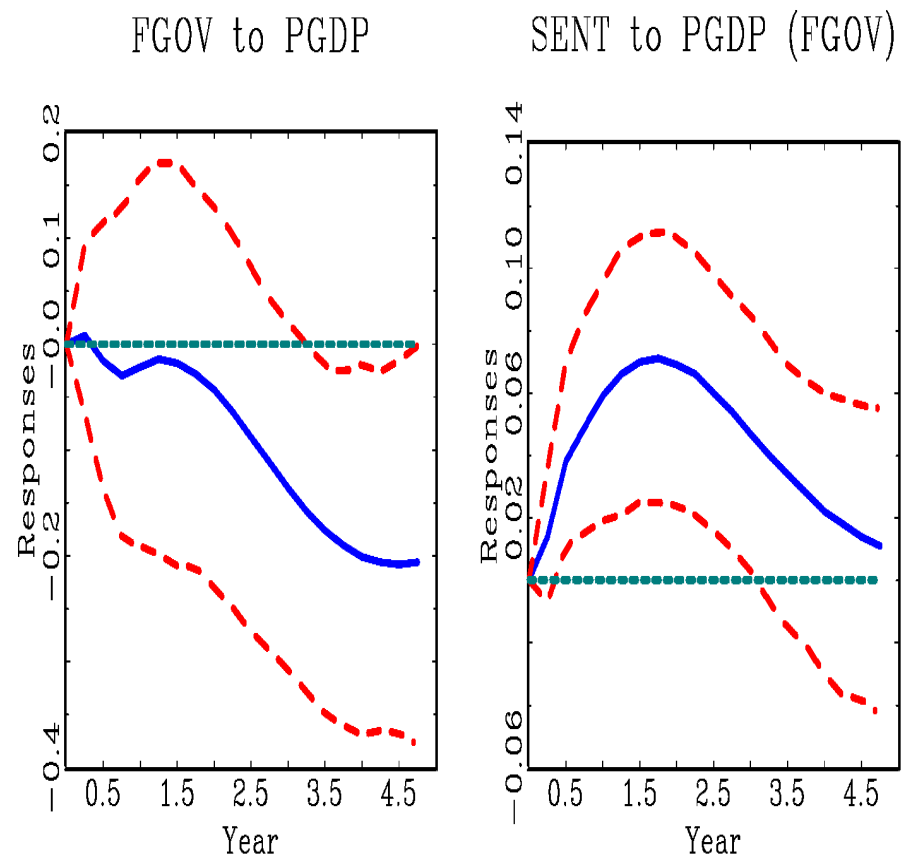

FGOV to SENT
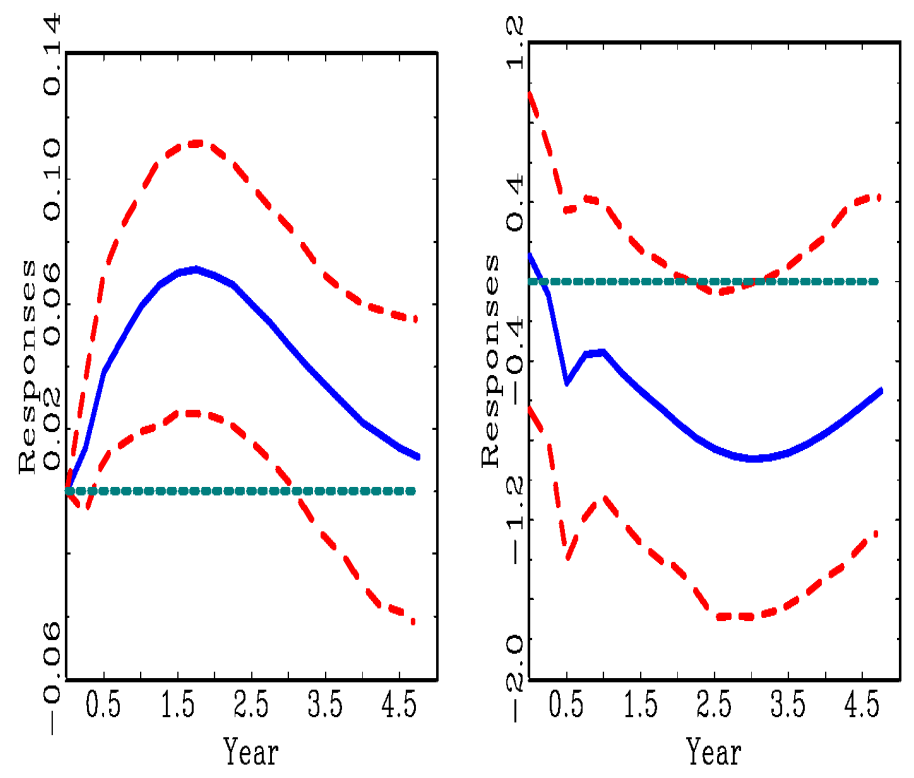

SPF to PGDP

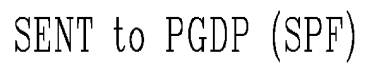

SPF to SENT
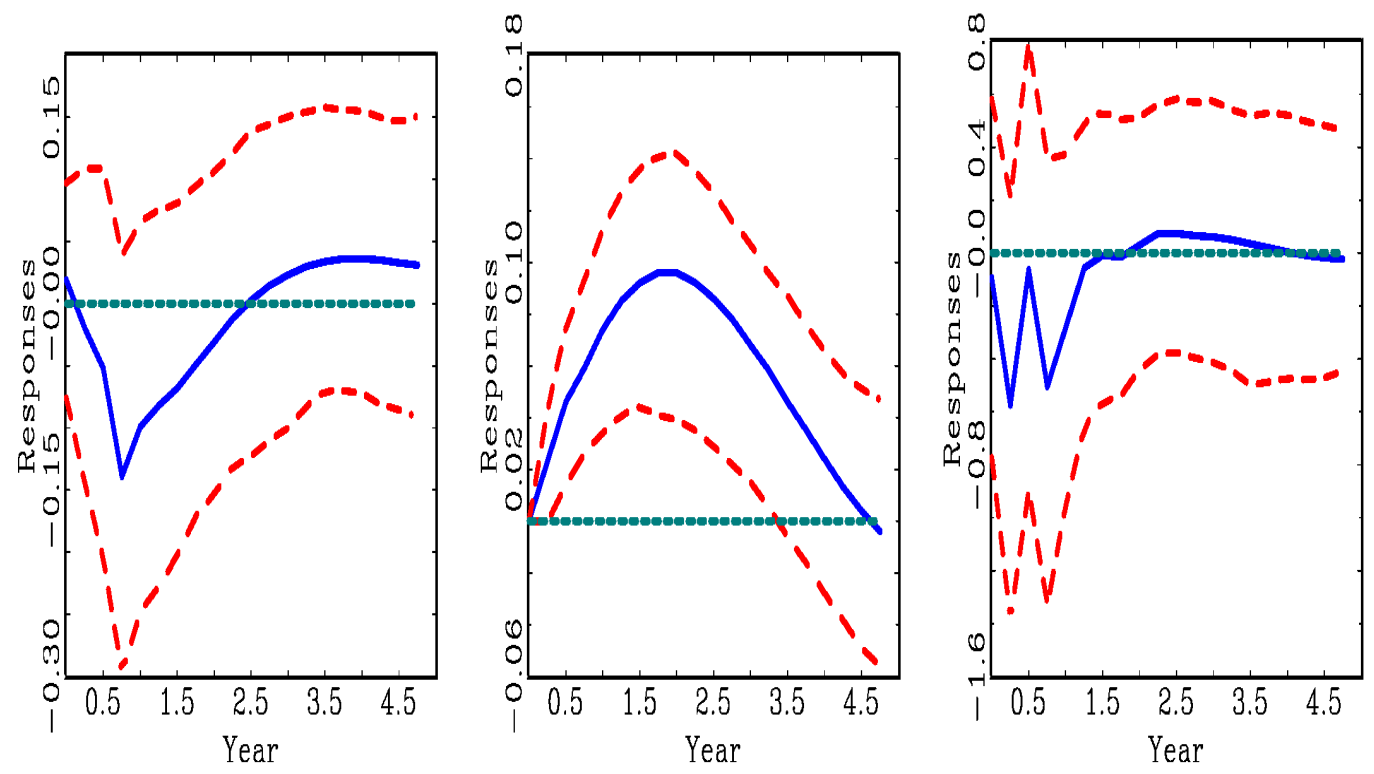

Note: Private GDP is the total GDP minus the total government consumption and gross investment expenditures. All spending variables are in real per capita terms. Solid lines are the impulse-reponse function point estimates from each model. Dashed lines are the $95 \%$ confidence band obtained from 500 nonparametric bootstrap simulations from empirical distributions. 
Figure 2. Responses of Private Acitivity
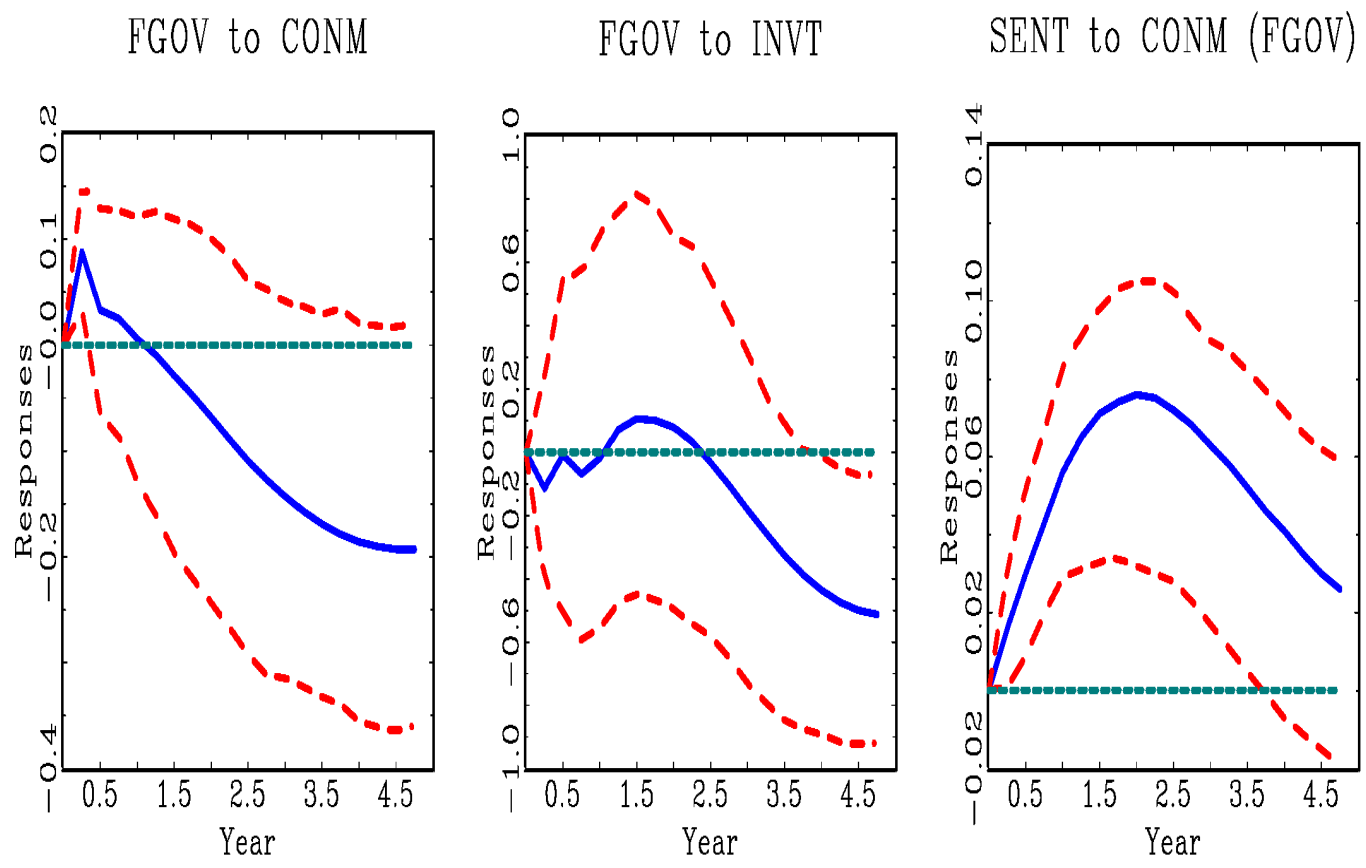

SPF to CONM

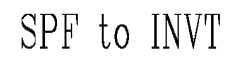

SENT to INVT (SPF)
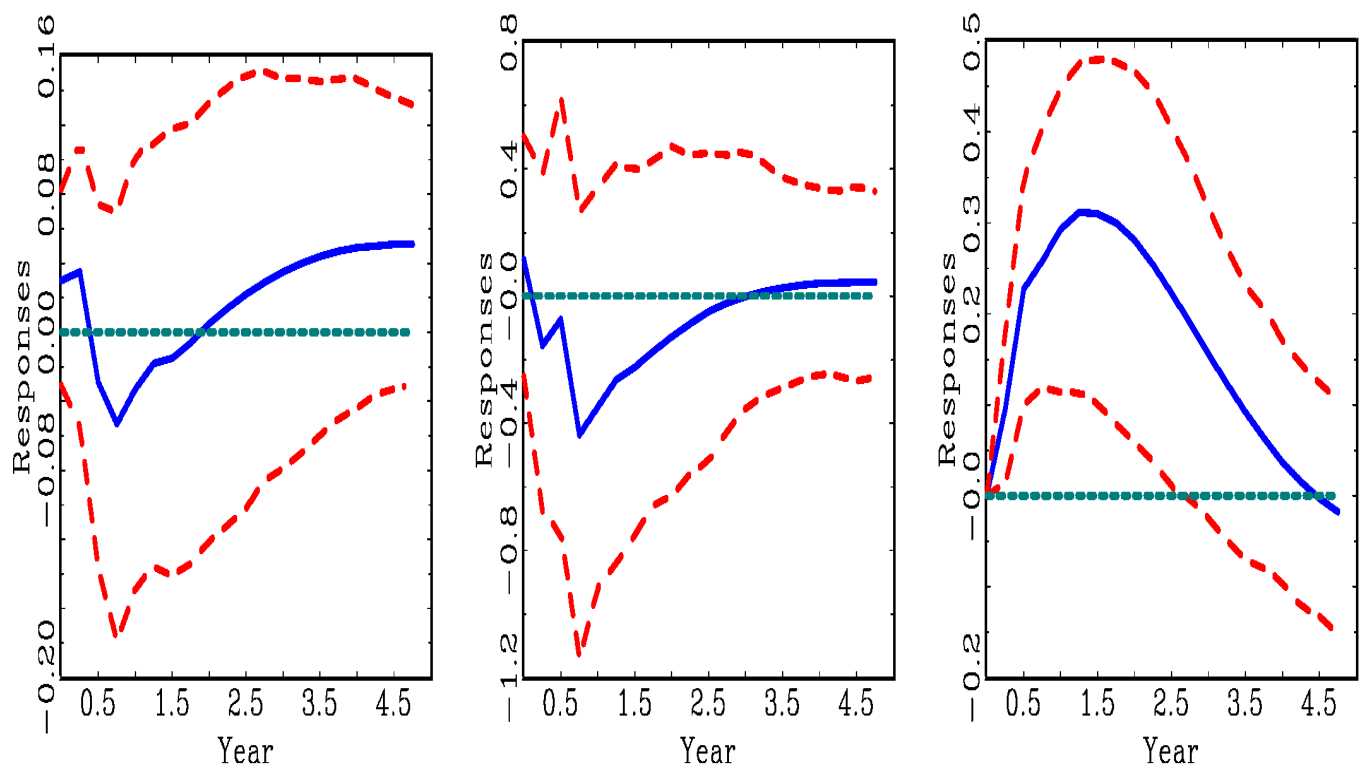

Note: Solid lines are the impulse-reponse function point estimates from each model. Dashed lines are the $95 \%$ confidence band obtained from 500 nonparametric bootstrap simulations from empirical distributions. 
Figure 3. Responses of Consumption: Durable vs. Nondurable Goods

FGOV to COND

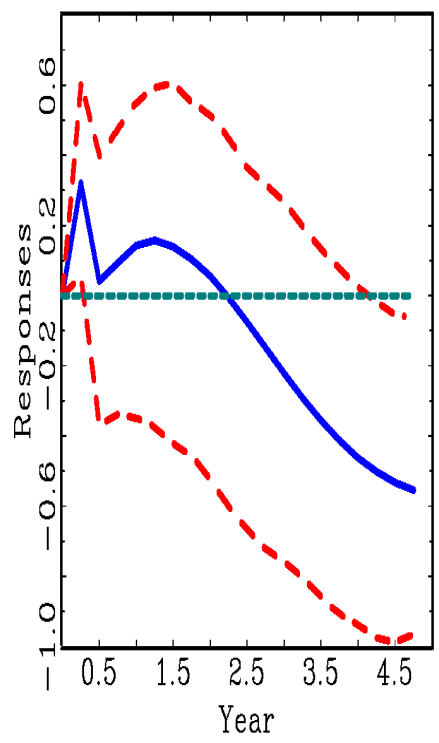

SPF to COND

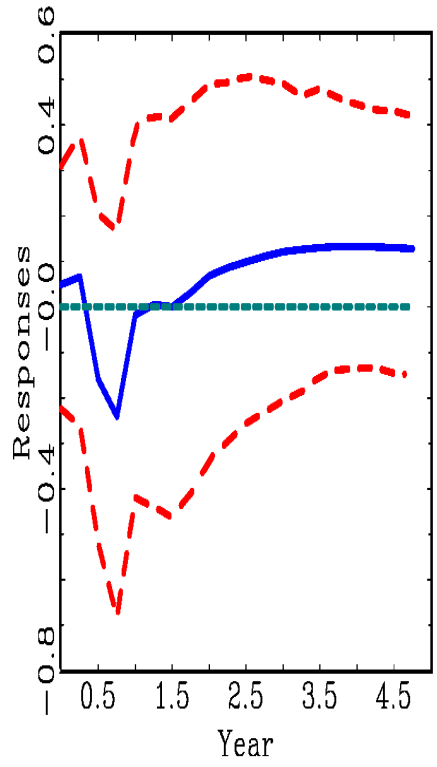

FGOV to CONN

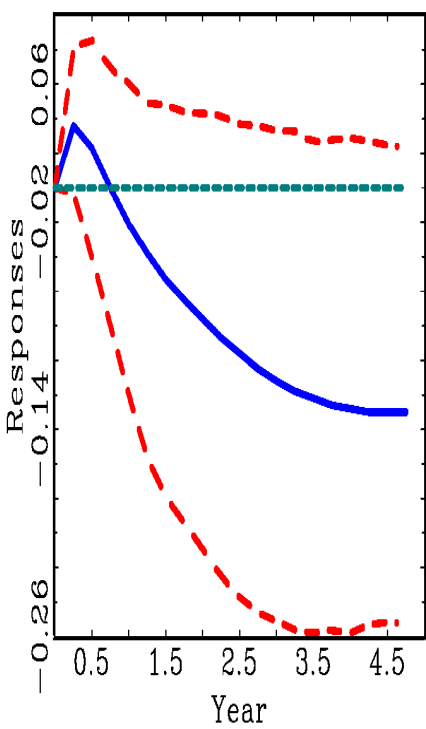

SPF to CONN

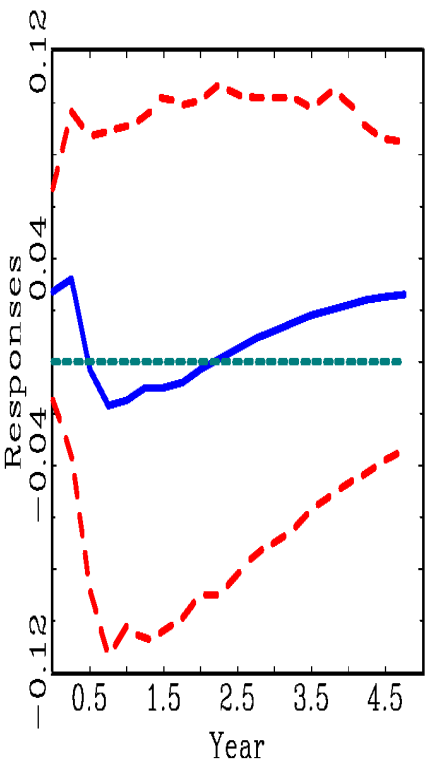

SENT to CONN (FGOV)

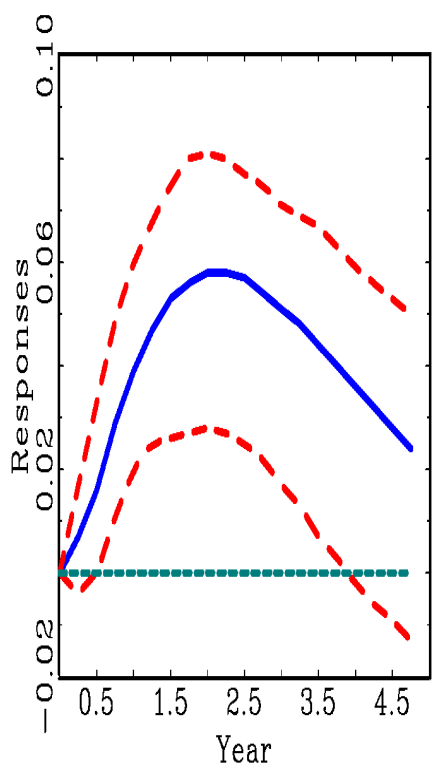

SENT to CONN (SPF)

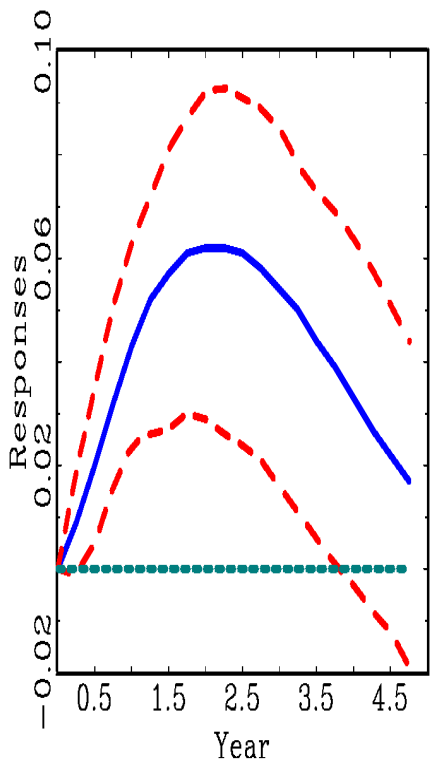

Note: Solid lines are the impulse-reponse function point estimates from each model. Dashed lines are the $95 \%$ confidence band obtained from 500 nonparametric bootstrap simulations from empirical distributions. 


\section{Figure 4. Robustness Check Analysis: 30-Year Rolling Window Scheme}

FGOV to PGDP

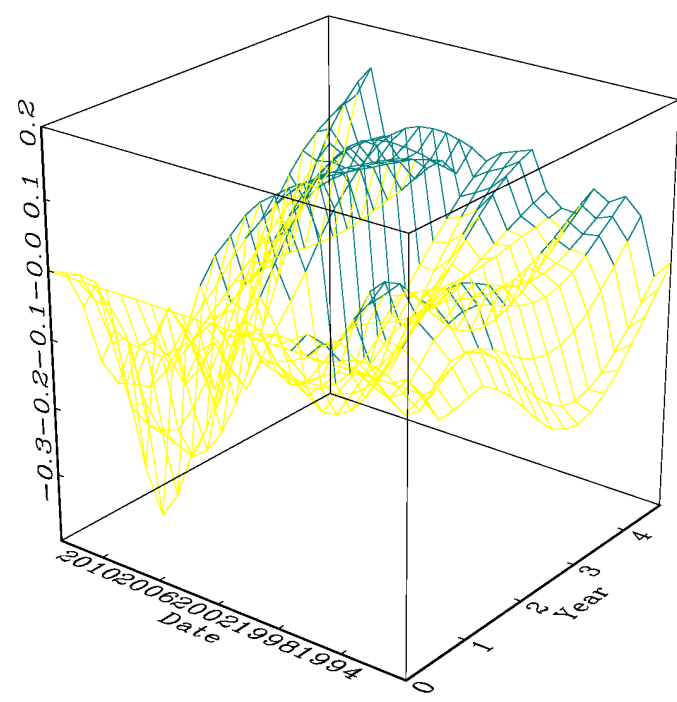

SPF to PGDP

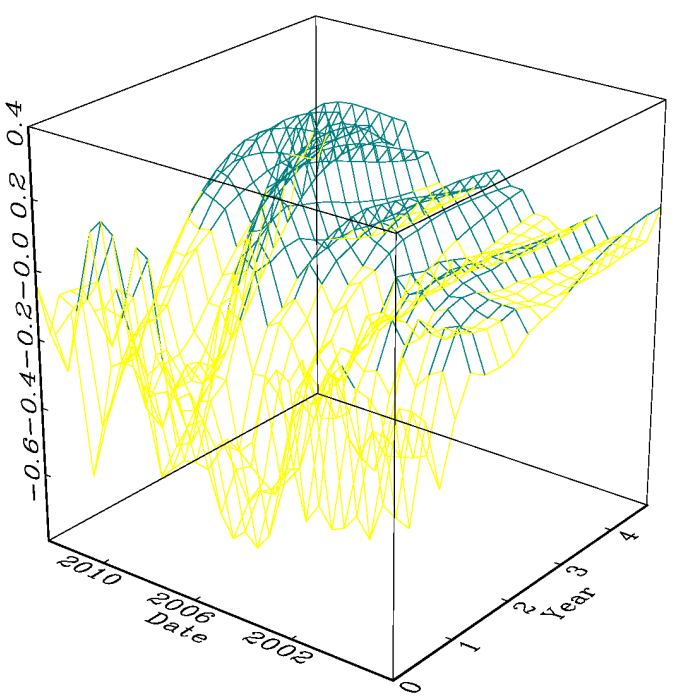

Note: We estimate and report surface graphs of the impulse response function with a 30-year fixed size rolling window scheme. That is, we begin the estimation with a sample period from 1960Q1 to 1989Q4, then we move the sample period forward by one quarter and estimate the IRFs again. We repeat until we reach the sample period from 1983Q3 to 2013Q2, which is used to estimate the last set of the IRFs. Lighter areas denote negative responses, whereas darker areas are positive responses. 
Figure 5. Trend in GDP and Government Spending
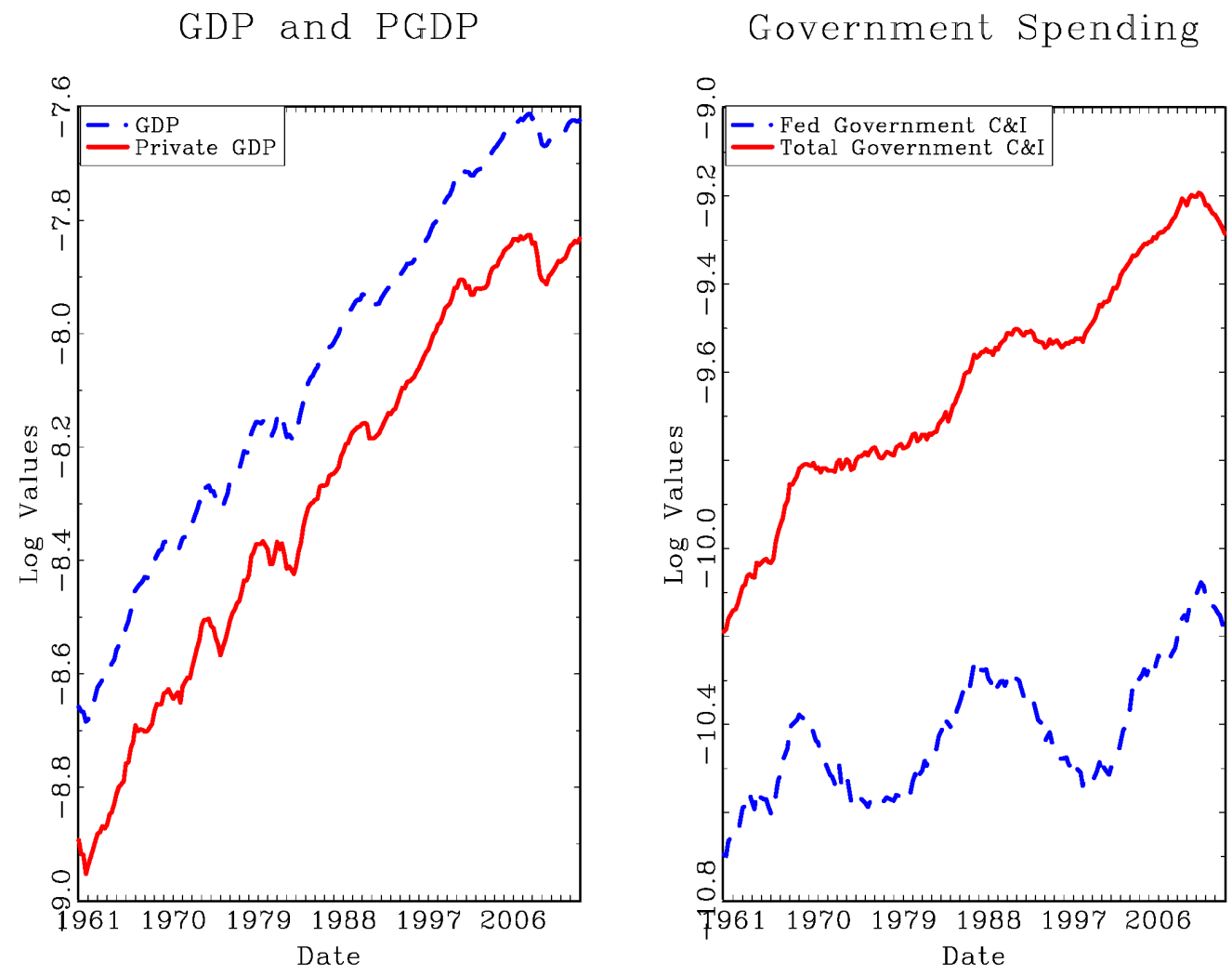

Notes: All spending variables are in real per capita terms and log-transformed. 
Figure 6. Nonlinear Responses of GDP

FC\&I to PGDP

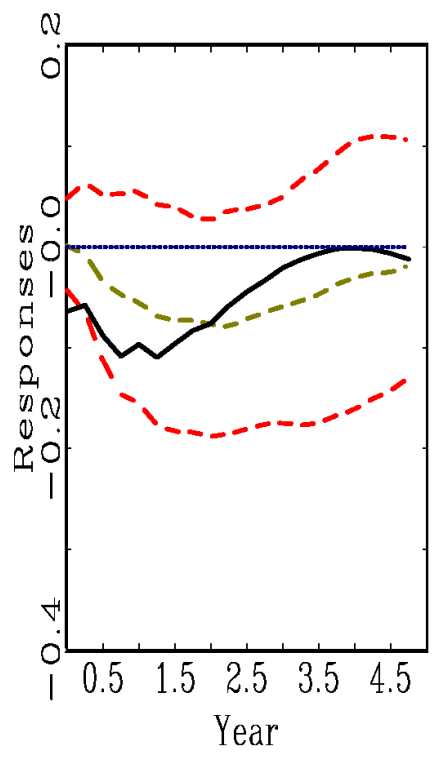

FC\&I to GDP

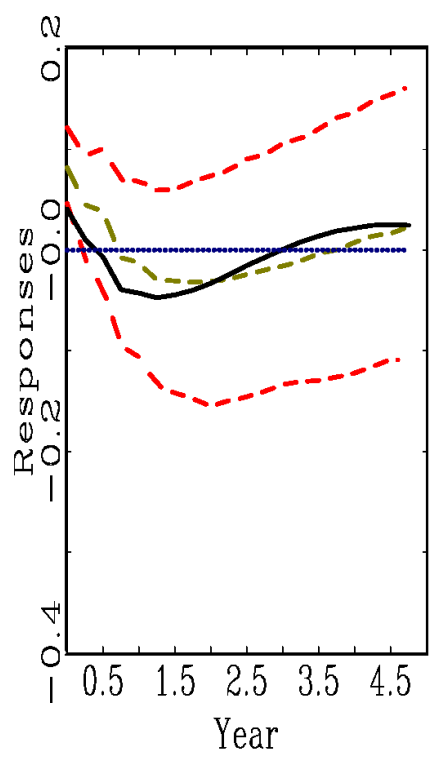

DEFN to PGDP

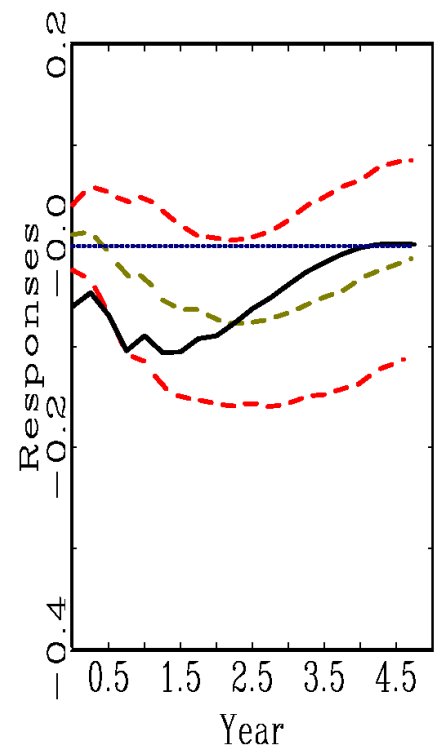

DEFN to GDP

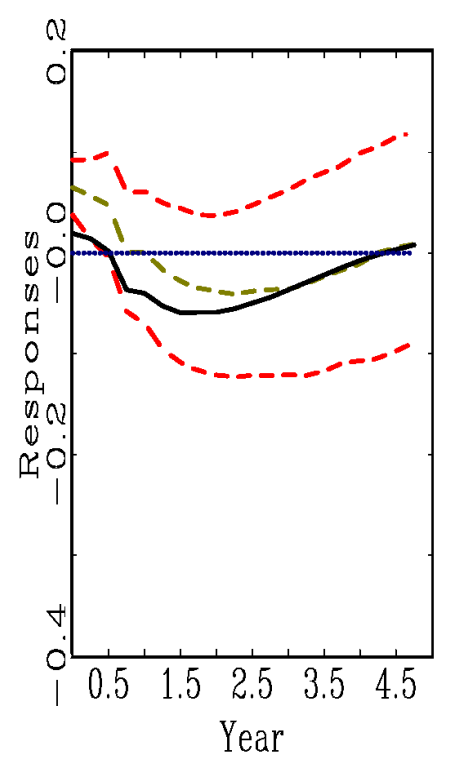

FGOV to PGDP

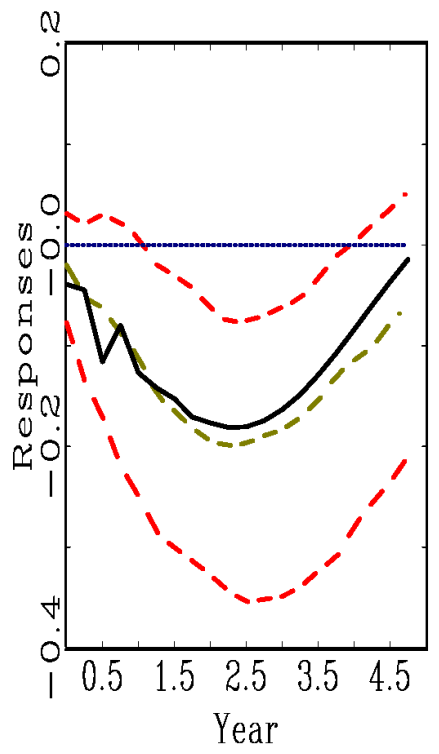

FGOV to GDP

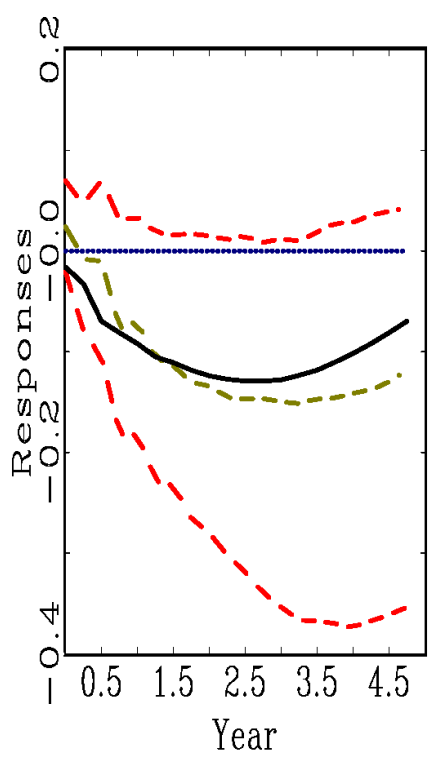

Note: We report the estimates obtained from tri-variate VAR models using the same ordering in Bachman and Sims (2012), that is, government spending, sentiment, and the private/total GDP. Solid lines are response function estimates in the recession regime, while dashed lines are 15.87 percentiles, 50 percentiles, and 84.13 percentiles of the response function in the boom regime, which constitutes the one standard deviation confidence band, generated by 500 nonparametric bootstrap simulations. 
Figure 7. Nonlinear Responses of Sentiment

\section{FC\&I to SENT (PGDP) DEFN to SENT (PGDP) FGOV to SENT (PGDP)}
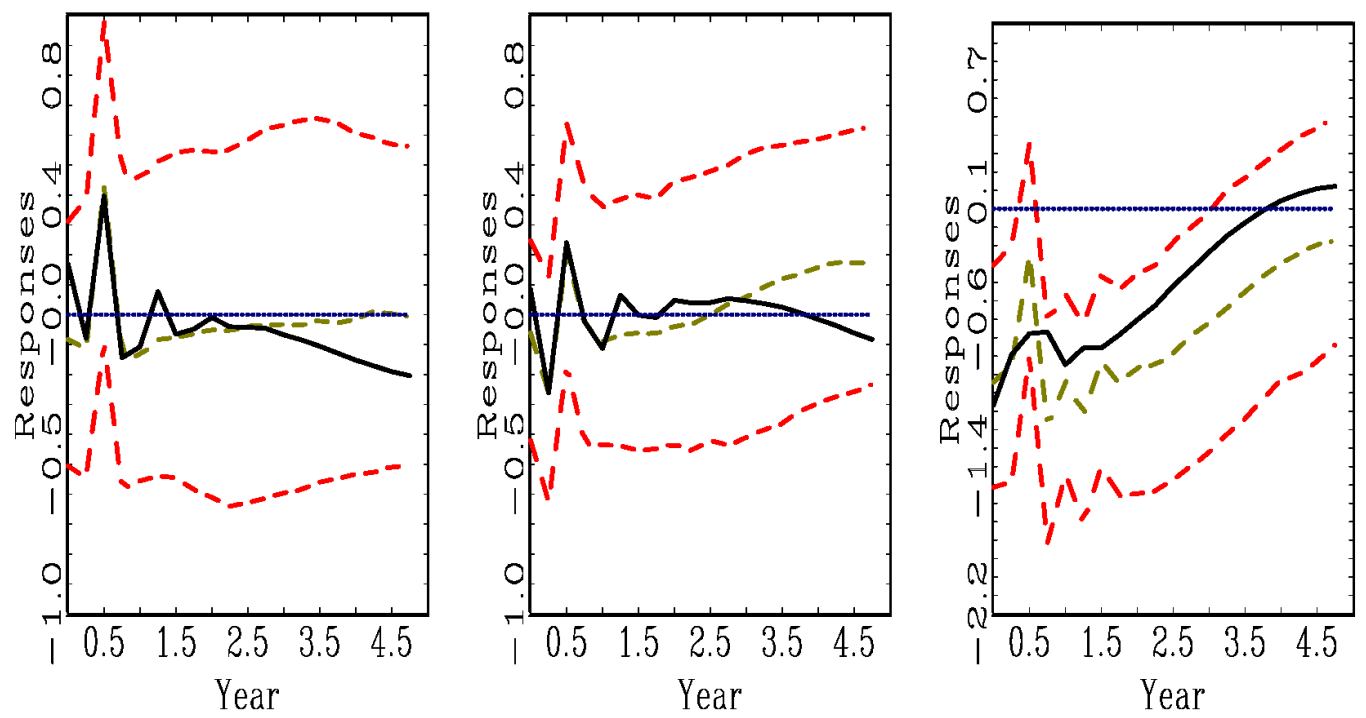

FC\&I to SENT (GDP)

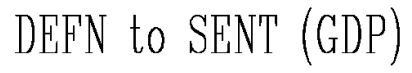

FGOV to SENT (GDP)
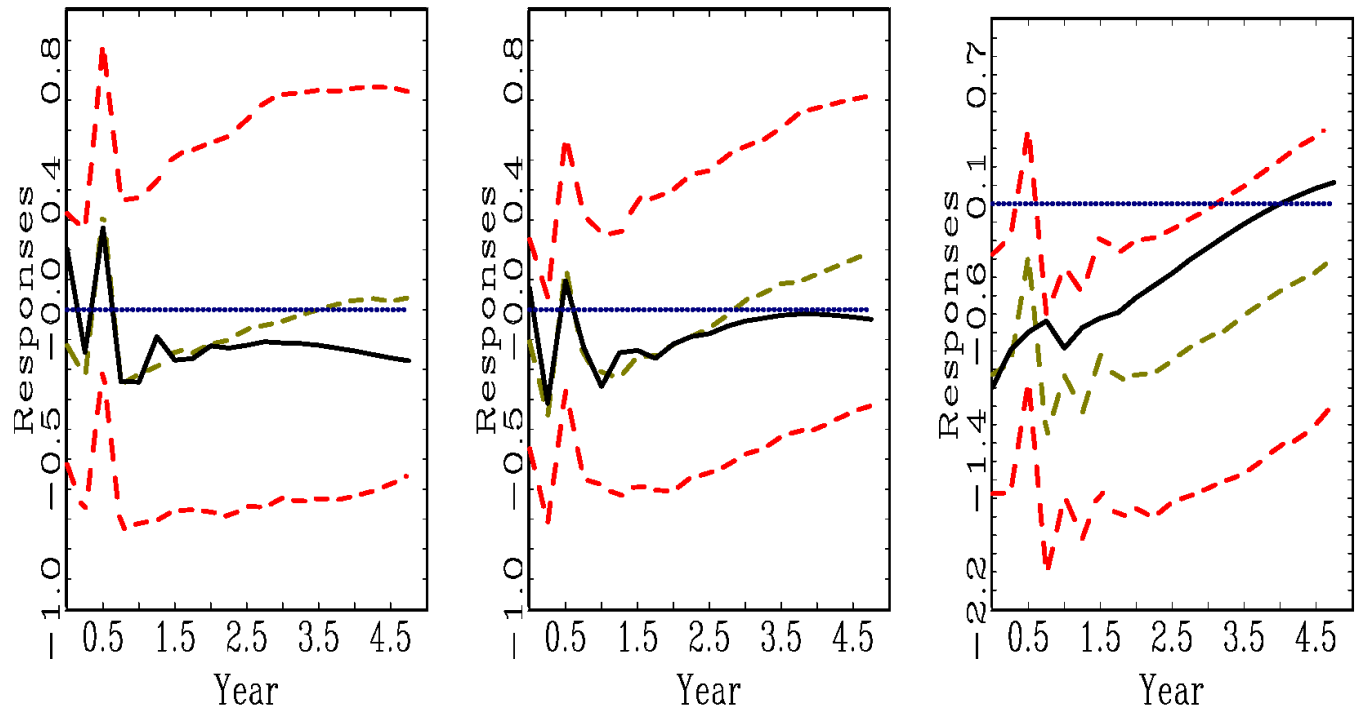

Note: We report the estimates obtained from tri-variate VAR models using the same ordering in Bachman and Sims (2012), that is, government spending, sentiment, and the private/total GDP. Solid lines are response function estimates in the recession regime, while dashed lines are 15.87 percentiles, 50 percentiles, and 84.13 percentiles of the response function in the boom regime, which constitutes the one standard deviation confidence band, generated by 500 nonparametric bootstrap simulations. 
Figure 8. Counterfactual Simulation Exercises with Alternative Identification Scheme

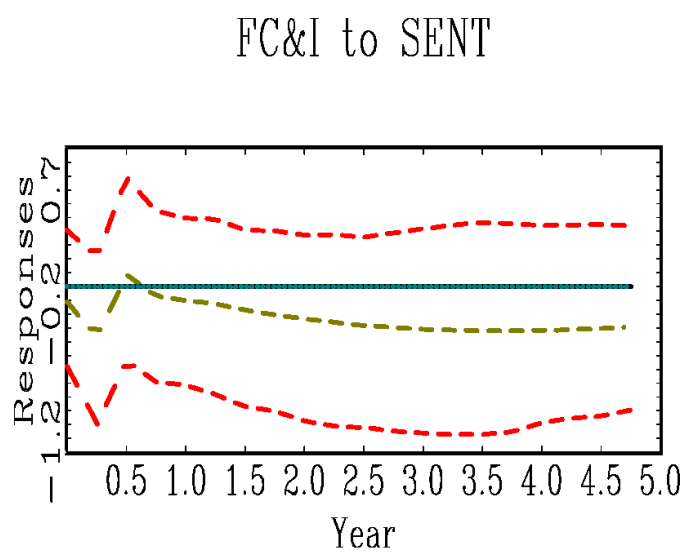

DEFN to SENT

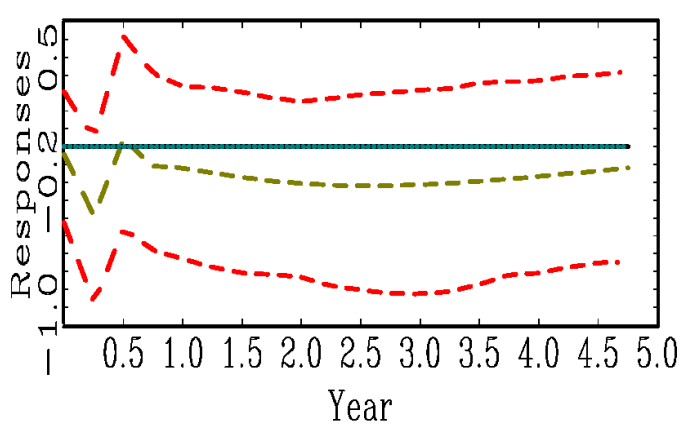

SC\&I to SENT

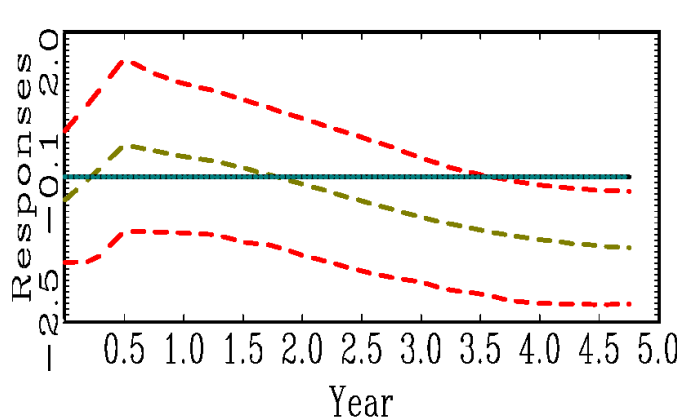

FC\&I to PGDP

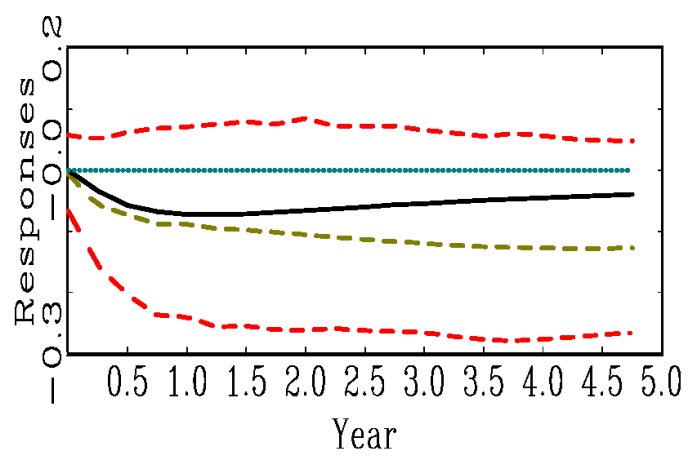

DEFN to PGDP

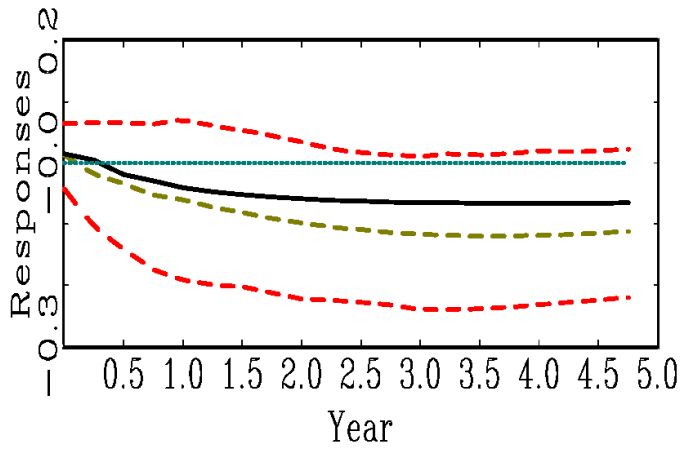

SC\&I to PGDP

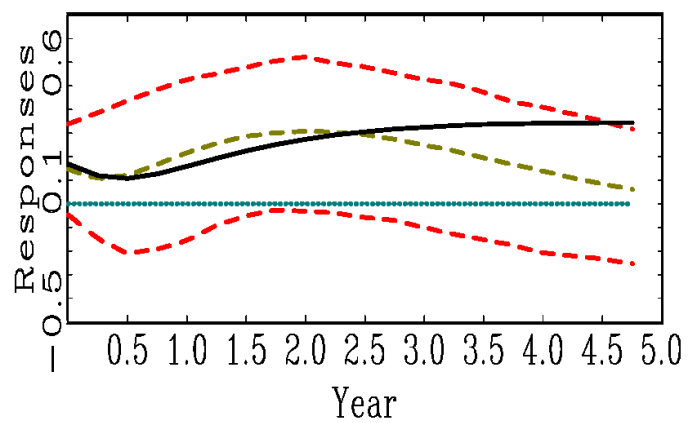

Note: We report the estimates obtained from tri-variate VAR models using the same ordering in Bachman and Sims (2012), that is, government spending, sentiment, and the private GDP. Solid lines are hypothetical response functions with additional sentiment shocks that are designed to hold sentiment unchanged for all forecast horizons. Dashed lines are the impulse-response function point estimate from unconstrained models accompanied by its $95 \%$ confidence bands. 